\title{
Seasonal variations in Greenland Ice Sheet motion: inland extent and behaviour at higher elevations
}

\author{
I. D. Bartholomew ${ }^{\mathrm{a}, *}$, P. Nienow ${ }^{\mathrm{a}}$, A. Sole ${ }^{\mathrm{a}}$, D. Mair ${ }^{\mathrm{b}}$, T. Cowton ${ }^{\mathrm{a}}$, M. A. \\ King $^{\mathrm{c}}$, S. Palmer ${ }^{\mathrm{d}}$ \\ ${ }^{a}$ School of Geosciences, University of Edinburgh, Drummond Street, Edinburgh, EH8 \\ $9 X P, U K$ \\ ${ }^{b}$ School of Geosciences, University of Aberdeen, Aberdeen, AB24 3UF, UK \\ ${ }^{c}$ School of Civil Engineering and Geosciences, Newcastle University, Newcastle upon \\ Tyne, NE1 $7 R U, U K$ \\ ${ }^{d}$ School of Earth and Environment, University of Leeds, Leeds, LS2 9JT, UK
}

\begin{abstract}
We present global positioning system observations that capture the full inland extent of ice motion variations in 2009 along a transect in the west Greenland Ice sheet margin. In situ measurements of air temperature and surface ablation, and satellite monitoring of ice surface albedo and supraglacial lake drainage are used to investigate hydrological controls on ice velocity changes. We find a strong positive correlation between rates of annual ablation and changes in annual ice motion along the transect, with sites nearest the ice sheet margin experiencing greater annual variations in ice motion (15-18\%) than those above $1000 \mathrm{~m}$ elevation (3 - 8\%). Patterns in the timing and rate of meltwater delivery to the ice-bed interface provide key controls on the magnitude of hydrologically-forced velocity variations at each site. In the lower ablation zone, the overall contribution of variations in ice motion to annual flow rates is limited by evolution in the structure of the
\end{abstract}

\footnotetext{
${ }^{*}$ Corresponding author

Email addresses: ian.bartholomew@ed.ac.uk (I. D. Bartholomew)
} 
subglacial drainage system. At sites in the upper ablation zone, a shorter period of summer melting and delayed establishment of a hydraulic connection between the ice sheet surface and its bed limit the timeframe for velocity variations to occur. Our data suggest that land-terminating sections of the Greenland Ice Sheet will experience increased dynamic mass loss in a warmer climate, as the behaviour that we observe in the lower ablation zone propagates further inland. Findings from this study provide a conceptual framework to understand the impact of hydrologically-forced velocity variations on the future mass balance of land-terminating sections of the Greenland Ice Sheet.

Key words:

\section{1. Introduction}

2 Our ability to make robust predictions about the future mass balance 3 of the Greenland Ice Sheet (GrIS), and therefore its contribution to sea-

4 level change, is limited by uncertainty about how the dynamic component 5 of mass loss (i.e. due to changes in ice motion) will respond to anticipated 6 changes in atmospheric temperature (IPCC, 2007; Pritchard et al., 2009). In

7 land-terminating sections of the GrIS, variations in ice velocity are initiated

8 when surface meltwater gains access to the ice-bed interface, lubricating

9 basal motion (Zwally et al., 2002; Van de Wal et al., 2008; Joughin et al., 10 2008; Shepherd et al., 2009; Bartholomew et al., 2010). This effect is both 11 widespread (Joughin et al., 2008; Sundal et al., 2011) and persistent each 12 summer (Van de Wal et al., 2008; Sundal et al., 2011; Zwally et al., 2002) 13 near the ice sheet margin. Initial observations show that summer velocities 14 in land-terminating sections of the GrIS can be $50 \%$ faster than in winter 15 (Van de Wal et al., 2008; Joughin et al., 2008), and that summer velocity 
41 Wal et al., 2008). By extension, it has been argued that summer, and there-

42 fore annual mean ice velocities at a given site on the GrIS could be lower 
43 in high ablation years than in low ablation years because channelisation of

44 the subglacial hydrological system occurs more quickly (Truffer et al., 2005;

45 Pimentel and Flowers, 2010; Sundal et al., 2011).

46

A key feature of hydrologically-forced velocity variations in the GrIS is 47 also that they propagate inland from the ice sheet margin on a seasonal

48 basis, in response to the onset of surface melting at successively higher

49 elevations (Bartholomew et al., 2010). The initiation of hydrologically-forced

50 ice velocity variations is dependent on the development of a conduit from the

51 ice sheet surface to allow surface meltwater to access the ice-bed interface.

52 In a warmer climate we expect summer melting of the GrIS to be more

53 intense, affecting a wider area for a longer time period than is currently the

54 case (Hanna et al., 2008), providing greater volumes of surface meltwater.

55 The melt regime will be amplified because the hypsometry of the GrIS,

56 which flattens inland, gives a non-linear expansion of the area of the GrIS

57 experiencing melt in response to a rise in the equilibrium-line altitude (ELA).

58 It is therefore possible that seasonal velocity variations in the GrIS will

59 propagate further inland in response to climate warming. One mechanism

60 to allow this is drainage of supraglacial lakes, which have the potential to

61 concentrate surface meltwaters into large enough reservoirs to propagate

62 fractures through ice that is $>1000 \mathrm{~m}$ thick (Alley et al., 2005; Das et al.,

63 2008; Krawczynski et al., 2009).

64 Current debates over whether increased melt rates across the GrIS will

65 induce greater dynamic mass loss can therefore be reduced to whether increased mass loss due to inland propagation of velocity variations in warmer

67 years will more than offset any potential reduction in mass loss due to ear-

68 lier onset of channelisation in the lower ablation zone. However, uncertainty

69 remains over the effect of increased meltwater production on dynamic be- 
haviour in the lower ablation zone - observations to date do not show conclusively whether annual mean ice velocities will increase or decrease in a warmer climate (Van de Wal et al., 2008; Joughin et al., 2008; Bartholomew et al., 2010; Sundal et al., 2011) and a more detailed understanding of the response of the subglacial drainage structure to large inputs of surface meltwater is required. In addition, while diurnal ice velocity variations have been observed up to $72 \mathrm{~km}$ from the GrIS margin in a short-term study (Shepherd et al., 2009), it is not clear that patterns in hydrologically-forced dynamic behaviour observed near the ice sheet margin are replicated at higher elevations. While singular lake drainage events have been described in detail (Das et al., 2008), it has not been shown that the integrated effect of widespread meltwater generation and lake drainage (McMillan et al., 2007; Box and Ski, 2007; Sundal et al., 2009) is a significant and sustained increase in glacier flow speed at higher elevations.

A secondary effect of meltwater inputs to the glacier system on ice dynamics is 'cryo-hydrologic warming', whereby heat conduction from water within the englacial system causes ice temperatures to be raised (Phillips et al., 2010). Increased temperatures will reduce ice viscosity and thus contribute to faster ice flow. It has been suggested that, in a warmer climate, drainage of meltwater into the ice sheet across a wider area will also cause a rapid thermal response in deep layers of the GrIS, compounding the effect of meltwater drainage on ice velocities (Phillips et al., 2010).

The aim of this study is to provide a clearer understanding of the mechanisms which control the magnitude and extent of hydrologically-forced dynamic behaviour at elevations up to and beyond the current ELA on a seasonal basis. This is motivated by the need to incorporate these processes in numerical models which predict the future evolution of the GrIS and the 
current lack of comprehensive empirical data with which to inform them (Parizek, 2010). The thermal effect of meltwater, which affects ice deformation rates rather than basal motion, does not have a significant seasonal signal (Phillips et al., 2010) and is not considered here.

We present continuous ice velocity measurements, derived from global position system (GPS) observations, that capture the full inland extent of seasonal velocity variations along a land-terminating transect at $\sim 67^{\circ} \mathrm{N}$ in western Greenland during the 2009 melt season (Figure 1). Measurements were made at seven sites up to 1716 m elevation, which is $\sim 115 \mathrm{~km}$ inland from the GrIS margin. The ice motion record is compared with in situ and satellite observations of air temperatures, surface melt characteristics and supraglacial lake evolution within the region of study, as well as with proglacial hydrological data (Bartholomew et al., in press).

\section{Data and Methods}

\subsection{GPS data}

We used dual-frequency Leica 500 and 1200 series GPS receivers to collect the season long records of ice motion at each site. Each GPS antenna was mounted on a pole drilled several metres into the ice, which froze in subsequently, providing measurements of ice motion that were independent of ablation. The GPS receivers collected data at 30 second intervals that were processed using a kinematic approach relative to an off-ice base station (King, 2004) using the Track 1.21 software (Chen, 1999; King and Bock, 2006). Conservative estimates of the uncertainty associated with positioning at each epoch are approximately $\pm 1 \mathrm{~cm}$ in the horizontal direction and $\pm 2 \mathrm{~cm}$ in the vertical direction. The data were smoothed using a Gaus- 
sian low-pass filter to suppress high-frequency noise without distorting the long-term signal. Daily horizontal velocities reported in this paper (Figure 2a-g) are calculated by differencing the filtered positions every 24 hours. Shorter-term variations in ice velocity were derived by differencing positions across a 6 hour sliding window, applied to the whole timeseries of filtered positions for each site. This window length was chosen in order to highlight short-term variations in the velocity records while retaining a high signal to noise ratio. Estimates of the magnitude of daily cylces in horizontal velocity are therefore minimum estimates. Unfortunately, the quality of the GPS data at site 1 was compromised by technical problems, and we are unable to resolve short-term variations in horizontal velocity at this site.

Uncertainties associated with the filtered positions are $<0.5 \mathrm{~cm}$ in the horizontal and $<1 \mathrm{~cm}$ in the vertical directions, corresponding to annual horizontal velocity uncertainties of $<3.7 \mathrm{~m} \mathrm{yr}^{-1}$ and $<14.6 \mathrm{~m} \mathrm{yr}^{-1}$ for the 24 hour and 6 hour velocity measurements respectively. We used the standard deviation of 24 hour and 6 hour sliding window velocities from site 7 , which has the longest processing baseline and experienced negligible velocity variations, to estimate the noise floor in the GPS velocity records. The standard deviations for 24 hour and 6 hour velocities at site 7 are $5.6 \mathrm{~m} \mathrm{yr}^{-1}$ and $19.5 \mathrm{~m} \mathrm{yr}^{-1}$ respectively. These values compare well with the calculated uncertainties and represent conservative error estimates for our dataset.

The values for winter background ice-velocities are derived from the displacement of each GPS receiver between the end of the summer melt season and the following spring (Bartholomew et al., 2010). The reported contribution to annual ice flux from the hydrologically-forced summer ice velocity variations is the percentage by which the observed annual displacement exceeds that which would occur if the ice moved at winter rates all year round. 


\subsection{Air temperate and surface ablation}

Simultaneous measurements of air temperature were made at each GPS site to constrain melt rates, and show that the velocity data cover the whole seasonal melt cycle. Measurements of air temperature were made using shielded Campbell Scientific T107 temperature sensors connected to Campbell Scientific CR800 dataloggers (sites 1, 3 and 6) and shielded HOBO U21-004 temperature sensors (sites 2, 4, 5 and 7) at 15 minute intervals throughout the survey period. Seasonal melt totals were also measured using ablation stakes at each GPS site.

\subsection{Proglacial discharge}

We made continuous measurements of water stage in the proglacial stream that emerges from the terminus of Leverett Glacier. Proglacial discharge was derived from a continuous stage-discharge rating curve calibrated with repeat dye dilution gauging experiments throughout the melt-season as described in detail in Bartholomew et al. (in press).

\subsection{Supraglacial lake evolution}

We used satellite observations from the Moderate-resolution Imaging Spectrometer (MODIS) to study the development of supraglacial lakes within the region of our GPS transect (Figure 1; delimited by the grey line). 20 MODIS images, spanning the period 31st May to 18th August 2009, were used, representing all the days when lake identification was not impeded by cloud cover. MODIS level 1B Calibrated Radiances (MOD02) were processed and projected as $250 \mathrm{~m}$ resolution true colour images in conjunction with the MODIS Geolocation product (MOD03), according to the methodology laid out by Gumley et al. (2003); see also Box and Ski (2007), and 
Sundal et al., (2009). Lakes were digitised manually in order to allow classification even on days of partial or thin cloud cover, producing a dataset with slightly higher temporal resolution than fully automated classification (Sundal et al., 2009). Drainage events were identified as occasions on which the area of a lake decreased to zero (or a very small fraction of its former size) without an intermediate period of refilling. Previous studies have found that MODIS classification of GrIS supraglacial lakes is robust when compared with higher resolution satellite data (Sundal et al., 2009) and has approximate error of $0.22 \mathrm{~km}^{2}$ per lake. However, since the lakes within this region are relatively small (typically $<1 \mathrm{~km}^{2}$ ) and there is considerable uncertainty in using a depth-retrieval algorithm to determine the depth of individual lakes (Box and Ski, 2007) we do not estimate individual lake volume. We note, however, that on the basis of a recent theoretical study of supraglacial lake drainage in the western GrIS (Krawczynski et al., 2009), any lake which is large enough to be resolved on MODIS images (theoretically one $250 \mathrm{~m} \times 250 \mathrm{~m}$ pixel $\left.\left(0.0625 \mathrm{~km}^{2}\right)\right)$ will contain enough water to drive a water-filled crack through $1 \mathrm{~km}$ of ice.

\subsection{Ice sheet surface characteristics}

We used the MYD10A1 1-day albedo product, part of the MODIS Aqua snow cover daily L3 global $500 \mathrm{~m}$ gridded product (Hall and Salomonson, 2009; Hall et al., 2009), to map changes in the albedo of the ice sheet surface in this region of the GrIS through the survey period. These data are used to quantify the lowering of surface albedo associated with meltwater generation and retreat of the seasonal snowline through the survey period. This product provides albedo values for pixels identified as cloud free and snow-covered on a $500 \mathrm{~m}$ grid derived from a snapshot taken once per day 
(Stroeve et al., 2006). We used 70 days of data, from April 22nd to September 20th, representing all the days on which the image was not obscured by cloud cover. This time period covers the whole melt season, from before the onset of melt at the ice sheet margin in spring, to the period of refreezing and snowfall in the autumn. In order to integrate the albedo characteristics across the region surrounding the transect, mean albedo was calculated by $50 \mathrm{~m}$ elevation bands in the study region using a surface digital elevation model (Palmer et al., 2011). Albedo thresholds for snow $(<0.45)$ and bare ice $(>0.66)$ surfaces were used to classify pixels on the basis of field observations along the nearby K-transect (Knap and Oerlemans, 1996). A resulting transitional band between the two zones is assumed to comprise a mixture of snow, ice with surface water and slush surfaces and broadly delimits the transient snowline (Knap and Oerlemans, 1996).

\section{Hydrological forcing of velocity variations}

Sites 1 - 6 all experience velocity peaks that are over $100 \%$ higher than their winter background values (Figure 2a-f). These variations begin nearest the margin on May 22nd, and propagate inland following the onset of surface melting up to a distance of $80 \mathrm{~km}$ from the GrIS margin in late July, at $1482 \mathrm{~m}$ elevation. Initial uplift of the ice sheet surface at each of these sites is interpreted to signal the establishment of a local hydraulic connection to the ice sheet bed (Iken et al., 1983; Zwally et al., 2002; Das et al., 2008; Anderson et al., 2004; Bartholomew et al., 2010). A high-velocity 'spring-event', accompanied by uplift of the ice sheet surface, characterises the start of locally-forced velocity variations at each of these sites in a manner similar to Alpine and High Arctic glaciers (Iken et al., 1983; Iken and 
Bindschadler, 1986; Mair et al., 2001; Bingham et al., 2008). This behaviour is consistent with inputs of meltwater to a subglacial hydrological system which is incapable of accommodating them without a great increase in pressure (Röthlisberger and Lang, 1987; Iken et al., 1983; Iken and Bindschadler, 1986; Hooke et al., 1989; Mair et al., 2001).

Although a small component of the coincident vertical and horizontal velocity changes is due to thickness changes resulting from longitudinal strainrate or stress-gradient coupling, the signals we observe cannot be attributed to these effects alone. Based on motion of adjacent sites and ice thickness data (Figure 1b; Bamber et al., 2001; Krabill, 2010), we calculate that the thickness changes originating due to longitudinal coupling are approximately an order of magnitude smaller than the elevation changes we have recorded. They also typically operate in the opposite direction as acceleration of downstream sites causes extension and thinning of ice upstream as opposed to the uplift observed. Throughout the summer, further speed-up events which are coincident with ice surface uplift confirm the role of surface generated meltwater in forcing seasonal changes in ice motion for this section of the GrIS. We also note that the evidence for hydraulically-forced enhanced basal motion implies that basal temperatures along this transect are at the pressure melting point.

Immediately prior to the spring events most sites also experience a short period of increased velocity in the absence of uplift of the ice surface, which we attribute to mechanical coupling to ice downglacier that is already moving more quickly (Price et al., 2008). At site 7, which is located at $1716 \mathrm{~m}$ elevation, $115 \mathrm{~km}$ from the margin, there is no surface uplift or significant ice acceleration indicating that surface generated meltwater did not penetrate to the bed this far inland (Figure $2 \mathrm{~g}$ ). Site 7 does display a small, but 
clear, change in horizontal velocity (Figure 3), however, which can likely be attributed to coupling to ice downstream. Since the magnitude of these changes is insignificant in terms of annual ice flux, site 7 delimits the inland extent of hydrologically forced velocity variations in 2009 for this transect.

\subsection{Behaviour in the lower ablation zone}

At sites $1-3$, which are low in the ablation zone and experience the greatest acceleration, spring-events occur early in the melt-season, near the beginning of June, and ice velocity become less sensitive to air temperature variations as the melt season progresses (Figure 2). This behaviour is explained by evolution in the structure of the subglacial drainage system in response to sustained inputs of meltwater from the ice sheet surface, consistent with previous observations and predictions of dynamic behaviour in this section of the GrIS (Bartholomew et al., 2010; Pimentel and Flowers, 2010).

A recent hydrological study (Bartholomew et al., in press) supports the conclusion that evolution in the structure of the subglacial drainage system is responsible for limiting the magnitude of hydrologically-forced velocity variations at sites 1 - 3 later in the melt season. Observations of hydrological parameters from a catchment that drains through Leverett Glacier show that an efficient subglacial drainage system expands upglacier at the expense of an inefficient one as the summer progresses, a process that has been observed previously on Alpine glaciers (Nienow et al., 1998). Episodic increases in the runoff hydrograph (Figure 2h), which are interpreted as evidence for dramatic re-organisation and expansion of the subglacial drainage system in response to new inputs of meltwater from the ice sheet surface, have a clear short-lived effect on the velocity records at sites 1, 2 and 3 
(Figure 2a-c,h). These events indicate, firstly, that sites $1-3$ are within the hydrological catchment of the river and, secondly, that changes in the subglacial drainage system have a direct impact on ice velocity downglacier from where they initially occur. The large volumes of water exceed the capacity of the subglacial drainage system, causing pressurisation, and a concomitant reduction in basal drag (Iken and Bindschadler, 1986), as the water is transported to the ice sheet margin.

Clear daily-cycles in horizontal velocity occur at sites 2 and 3 following the spring events, and persist until mid-August. The magnitude of these cycles is typically between 100 and $150 \%$ of the mean daily velocity, and can be over $200 \%$ of winter background velocity during periods of significantly enhanced motion (Figure 4). Their existence indicates that over-pressurisation of the subglacial drainage system also happens regularly on diurnal timescales. The daily cycles in ice velocity appear to be closely related to variations in air temperature, with a typical lag between peak temperature and peak velocity of less than 3 hours, suggesting that they occur in direct response to diurnal variations in meltwater production at the ice sheet surface and that surface and englacial transit times are short (Shepherd et al., 2009).

In addition to these short-lived events, ice velocities at sites 1,2 and 3 are higher on the rising limb of the seasonal runoff hydrograph for Leverett Glacier, subdued following peak discharge on July 21st, and display a return to winter background rates in late August, when runoff is diminishing (Figure 2a-c. h). 'Slower than winter' ice velocities are also observed for a short period at some sites once the summer melt has stopped, however this signal is not large enough to have a significant impact on rates of annual ice motion. 
These findings from the lower ablation zone can be explained in physical terms. Although increased efficiency of the subglacial hydrological system reduces the dynamic response to absolute water input volume (Bartholomew et al., 2010), lake drainage and other singular high velocity events, as well as diurnal fluctuations in horizontal velocity testify that the system can still be overfilled by a large enough increase in meltwater input, causing an increase in subglacial water pressure (Das et al., 2008; Shepherd et al., 2009; Pimentel and Flowers, 2010; Schoof, 2010). Production of surface meltwater, and its delivery to the ice-bed interface, is inherently variable on timescales of hours, days, weeks and months. Since the capacity of the subglacial hydrological system reflects the balance between channel opening by melting of the channel walls, and closure due to deformation of the surrounding ice, and adjusts relatively slowly to changes in water flux (Röthlisberger, 1972; Schoof, 2010), the system never reaches steady-state. We argue, therefore, that once a conduit has been established to deliver surface meltwater to the glacier bed, large changes in the rate of meltwater delivery to the subglacial hydrological system will continue to force velocity variations.

This analysis explains why high-velocity events at sites 1, 2 and 3 occur on the rising limb of the discharge hydrograph, when the system is continuously challenged to evacuate larger and larger volumes of water. Later in the season, when a channelised drainage system has been established, and volumes of meltwater are diminishing, the drainage system is better able to evacuate meltwater without overfilling, explaining the reduction in magnitude of hydrologically-forced variations in ice motion. While ice velocities are subdued on the falling limb of the runoff hydrograph, velocities at sites 1 - 3 still exceed winter flow rates until mid-August. This appears to be the result of continued diurnal fluctuations in ice velocity (Figure 4), which oc- 
cur until there is a dramatic reduction in runoff volumes at Leverett glacier after August 15th (Bartholomew et al., in press).

\subsection{Behaviour in the upper ablation zone}

At sites $4-6$, which are higher in the ablation zone $(>1000 \mathrm{~m})$, the relationship between changes in the rate of horizontal motion and the rate of uplift of the ice sheet surfaces indicates that the forcing mechanism is the same as in the lower ablation zone. Mapping of surface albedo using satellite data shows that the observed spring-events at these sites follow the onset of surface melting above their respective elevations (Figure 5), although both satellite and in situ observations showed that the snowpack was not fully removed at sites 5 and 6 by the end of the summer.

A key difference from the lower ablation zone is that the spring events occur later in the melt season (Figure 2a-g). There is also a significant time lag between the onset of surface melting, as inferred from both positive degree days (PDD's) and MODIS-derived albedo values, and the establishment of a hydraulic connection between the ice sheet surface and its bed as inferred from uplift of the ice surface. This means that significant velocity enhancement occurs for a much shorter time period than at lower elevations. At site 4, surface melting begins in early June, while coincident surface uplift and horizontal acceleration, which are diagnostic of local hydrological-forcing, are delayed until July 5th (Figure 2d). Increased velocities prior to this date, which occur without accompanying surface uplift, are explained by coupling to downglacier ice and are not as large as those induced by local forcing at the sites nearer the margin. In situ measurements of air temperature and satellite observations of surface albedo show that sites 5 and 6 both experience prolonged surface melting from July 6 th onwards, and experience 
locally-forced velocity variations from July 12th and July 27th respectively (Figure 2e,f). Later spring events and the delay between the onset of surface melting and hydraulic connection between the ice surface and its bed are due in part to lower rates of surface melting. In addition greater volumes of water are required to propagate fractures through thicker ice (Alley et al., 2005; Van der Veen, 2007). These factors both increase the time required for the accumulation of sufficient volumes of meltwater to penetrate to the ice sheet bed.

Sites 4, 5 and 6 all experienced their highest velocities during a period of cooler temperatures from July 22nd to August 2nd (Figure 2d-f), suggesting that drainage of stored surface water was a key factor in these hydrologically-forced events. Satellite images show surface meltwater accumulation in supraglacial lakes in this region from mid-June at elevations between 1000 - $1200 \mathrm{~m}$, and from $1200 \mathrm{~m}$ to >1600 m from early July. This storage of surface meltwater is made possible by relatively low surface gradients, which reduce the tendency for water to runoff to lower elevations (Nienow and Hubbard, 2006), and allows concentration of the large volumes of water required to propagate fractures to the ice sheet bed through thick ice (Das et al., 2008; Box and Ski, 2007; McMillan et al., 2007; Sundal et al., 2009)

Using MODIS imagery, we identify a number of events where changes in horizontal and vertical movement at one or more of our GPS sites is coincident with the disappearance of supraglacial lakes from the ice sheet surface. In particular, the spring event at site 5 on July 12 th is coincident with disappearance of three supraglacial lakes from between 1200 - $1350 \mathrm{~m}$ elevation (Figure 1, yellow). Widespread drainage of supraglacial lakes at elevations up to 1500 m between July 19th - 23rd (Figure 1, red) corresponds 
with increases in ice velocity at sites 4 and 5 of up to $100 \mathrm{~m} \mathrm{y}^{-1}$ on July 21st and 22nd respectively. The peak in horizontal velocities at sites 4,5 and 6 at the end of July also coincides with drainage of a lake at $\sim 1400 \mathrm{~m}$ elevation and a number of lakes above $\sim 1500 \mathrm{~m}$ between July 26th and July 29th (Figure 1, blue). It is not possible to be certain, using optical imagery, that all lakes which disappear from the ice sheet surface drain directly into englacial conduits. For example, some lakes may drain superficially either into other lakes or to join with a water input point further downglacier. However, the repeated coincidence of lake disappearance from the ice sheet surface with changes in ice velocities suggests strongly that a large number of these lakes drain to the ice-bed interface locally. Uplift of the ice surface indicates that this water is delivered to a subglacial drainage system which is unable to evacuate it without a large increase in water pressure, leading to the enhanced basal motion (Das et al., 2008).

Drainage of supraglacial lakes therefore appears to be responsible for the initiation of hydrologically forced velocity variations at both sites 5 and 6 . It is not clear that the spring event at site 4, on July 5th, is caused directly by drainage of supraglacial lakes. This site is located by a large moulin which becomes active each year (Catania and Neumann, 2010), and it is likely that the spring event is associated with the re-opening of this moulin. A common factor in the upper ablation zone, however, is that by the time a hydraulic connection has been established between the ice sheet surface and its bed, facilitating hydrologically-forced velocity variations, air temperatures and proglacial runoff are already decreasing. Lake drainage events are known to be rapid, delivering large enough volumes of water to quickly transform the subglacial hydrological system into an efficient channellised network (Das et al., 2008). Under these circumstances, it is unlikely that the volumes 
412 of water generated at the ice sheet surface at these elevations following

413 lake drainage events will be sufficient to sustain large velocity variations

${ }_{414}$ (Pimentel and Flowers, 2010). Accordingly, even though the temperature

415 data show considerable melting occurs at sites 4 and 5 until mid-August, we

416 do not observe any changes in ice velocity at sites above $1000 \mathrm{~m}$ elevation

417 beyond August 2nd.

418

419

420

421

422

423

424

425

426

427

428

429

\subsection{Changes in annual motion}

Annual mean ice velocities at sites 1 - 7 respectively are $16.7 \%, 18.4 \%$, $14.8 \%, 7.6 \%, 5.1 \%, 2.5 \%$ and $0.2 \%$ greater than they would be if the ice flowed at winter rates all year round. We find a strong correlation between the magnitude of local ablation and the percentage changes in annual ice motion due to hydrologically-forced velocity variations at each GPS site (Figure 6). Sites 1, 2 and 3, which are nearest the margin and below 800 $m$ elevation, experience the most surface melting and show significantly greater annual acceleration than those at higher elevations, with the effect attenuating inland. Data from 2008 also show increases in mean annual ice velocity of $13.5 \%$ and $5.6 \%$ at sites 3 and 4 respectively due to summer velocity variations (Bartholomew et al., 2010), indicating that the velocity changes that we observe in 2009 are a persistent feature of the dynamic behaviour of this part of the GrIS.

The relationship between rates of annual ablation and the amplitude of hydrologically-forced velocity change is not intuitive on the basis of previous theoretical work (Pimentel and Flowers, 2010) and observations (Van de Wal et al., 2008), which have suggested that higher volumes of surface meltwater production will ultimately reduce the impact of hydrological forcing on GrIS motion. Implicit in these arguments is a concept of 'optimum melt': 
too much meltwater and the hydrological system will become channelised earlier in the summer, making ice velocities less sensitive to the volumes of meltwater reaching the bed more quickly, reducing the impact of seasonal velocity variations on the annual displacement of the ice. However, it is important to consider that the hydrological forcing at each site is a product of both local melting and meltwater delivered through the subglacial drainage system from further upglacier. As a result, sites nearest the margin will receive disproportionately more meltwater per unit of local melting than those at higher elevations. Following this logic, previous theoretical work (Pimentel and Flowers, 2010) and observations (Van de Wal et al., 2008) expect sites nearest the margin, where the total flux of meltwater through the subglacial drainage system will be greatest, to show smaller overall velocity changes than sites further inland. However, despite significant differences in the local volume of meltwater delivered to the ice-bed interface, we see similar increases in annual ice motion at sites $1-3(14.8-18.4 \%)$.

Our findings from the lower ablation zone are consistent with the numerical model of subglacial drainage proposed recently by Schoof (2010) and suggest that hydrologically-forced ice velocity variations are controlled more strongly by variations in the rate, rather than the absolute volume, of meltwater production and delivery to the ice-bed interface. In particular, this reflects a temporary imbalance between the volume of water within the subglacial drainage system, and its inability to evacuate this water without an increase in pressure over a wide enough area to significantly affect basal motion (Kamb et al., 1994). We argue that in a warmer climate, where greater volumes of surface meltwater are produced in the lower ablation zone, the seasonal rising limb and shorter-term variations in water delivery to the subglacial drainage system will continue to cause significant increases in annual 
ice motion despite the potential for an earlier 'switch' from a distributed to a channelised subglacial drainage system (Schoof, 2010). However, the overall magnitude of velocity variations will continue to be limited by evolution in the structure of the subglacial drainage system, which responds to inputs of surface meltwater over a longer period (Mair et al., 2002; Anderson et al., 2004; Bartholomew et al., 2010; Schoof, 2010).

While development in the efficiency of the subglacial drainage system also exerts some control on hydro-dynamic behaviour at higher elevations, the dominant limiting factor on the contribution of velocity variations to annual ice motion at sites in the upper ablation zone is the shorter duration and later establishment of the hydraulic connection between the ice sheet surface and its bed. The expectation that surface melting will be more intense, and spatially extensive, in a warmer climate (Hanna et al., 2008), leads us to suggest that, in future, sites at higher elevations are likely to experience velocity variations for a longer period of time, allowing a greater annual change in ice velocity. In particular, higher rates of meltwater production would allow lakes that fill and subsequently drain to reach the volume required to propagate cracks through thick, cold ice earlier in the summer season (Krawczynski et al., 2009). We therefore expect that the behaviour observed at sites 1 - 3 would be extended to higher elevations, creating a positive relationship between atmospheric warming and dynamic mass loss in land-terminating sections of the GrIS, albeit one that is modified by development in the structure of the subglacial drainage system.

We do not infer direct cause and effect between bulk volumes of surface ablation and changes in ice motion on the basis of the relationship shown in Figure 6. Instead, our data show contrasting regimes in hydrologically-forced dynamic behaviour of the GrIS at different elevations within the ablation 
zone, which provide a compelling explanation for the relationship between total surface ablation and changes in annual ice motion. We therefore believe that our data provide a realistic basis for parameterisation of ice flow models that are used to predict the future evolution of the GrIS (Parizek and Alley, 2004).

\section{Conclusions}

Our data show that seasonal changes in horizontal ice velocity along a $\sim 115 \mathrm{~km}$ transect in a land-terminating section of the western GrIS, are forced by the generation of surface meltwater which is able to reach the ice-bed interface. These velocity variations propagate inland from the ice sheet margin to progressively higher elevations in response to the onset of surface melting, and the creation of a hydraulic connection between the ice sheet surface and its bed. We find a positive relationship between rates of annual ablation and percentage changes in annual ice motion along the transect, with sites nearest the ice sheet margin experiencing greater annual variations in ice motion (15-18\%) than those above $1000 \mathrm{~m}$ elevation (3$8 \%)$.

Patterns in the timing and rate of meltwater delivery to the ice-bed interface are key controls on the magnitude of hydrologically-forced velocity variations at each site. In the lower ablation zone ( $<800 \mathrm{~m}$ elevation), 'spring events' occur early in the melt season and the overall contribution of variations in ice motion to annual flow rates is limited by evolution in the structure of the subglacial drainage system (Bartholomew et al., 2010). At these sites, hydrologically-forced ice acceleration is greatest on the rising limb of the seasonal runoff hydrograph, when the hydraulic capacity of the 
subglacial drainage systems is consistently exceeded. However, we find that this behaviour is not replicated at sites in the upper ablation zone $(>1000$ $\mathrm{m})$, where the period of summer melting is shorter, and the establishment of a hydraulic connection between the ice sheet surface and its bed is delayed, limiting the timeframe for velocity variations to occur.

In a warmer climate we expect seasonal melting of the GrIS surface to extend over a wider area, and to be more prolonged (Hanna et al., 2008). This makes it likely that volumes of meltwater sufficient to reach the icebed interface will accumulate further from the ice sheet margin and that the timing of meltwater input will occur earlier each summer (Sundal et al., 2009; Krawczynski et al., 2009). Our data therefore support the hypothesis that inland propagation of hydrologically-forced velocity variations will induce greater dynamic mass loss in land-terminating sections of the GrIS in a warmer climate, as patterns of hydro-dynamic behaviour observed in the lower ablation zone extend upglacier. These considerations provide a conceptual framework to understand the positive relationship between annual rates of surface ablation and percentage variations in annual ice velocity, and can be used to improve numerical simulations used for predicting the impact of hydrologically-forced variations in ice velocity on the future mass balance of the GrIS (Parizek, 2010).

\section{Acknowledgements}

We thank for financial support: UK Natural Environment Research Council (NERC, through a studentship to IB and grants to PN and DM), Edinburgh University Moss Centenary Scholarship (IB). GPS equipment and training were provided by the NERC Geophysical Equipment Facility. 
${ }_{542}$ MAK was funded by a RCUK Academic Fellowship. ERS SAR data, for

the surface DEM, were provided by the European Space Agency VECTRA project (SP).

\section{References}

Alley, R., Dupont, T., Parizek, B., Anandakrishnan, S., 2005. Access of surface meltwater to beds of sub-freezing glaciers: preliminary insights. Annals of Glaciology 40 (1), 8-14.

Anderson, R., Anderson, S., MacGregor, K., Waddington, E., O’Neel, S., Riihimaki, C., Loso, M., 2004. Strong feedbacks between hydrology and sliding of a small alpine glacier. Journal of Geophysical Research 109.

Bamber, J., Layberry, R., Gogineni, S., 2001. A new ice thickness and bed data set for the Greenland ice sheet: I. Measurement, data reduction, and errors. Journal of Geophysical Research. D. Atmospheres 106, 33.

Bartholomew, I., Nienow, P., Mair, D., Hubbard, A., King, M., Sole, A., 2010. Seasonal evolution of subglacial drainage and acceleration in a Greenland outlet glacier. Nature Geoscience 3, 408-411.

Bartholomew, I., Nienow, P., Sole, A., Mair, D., Cowton, T., Palmer, S., Wadham, J., in press. Supraglacial forcing of subglacial hydrology in the ablation zone of the Greenland Ice Sheet. Geophysical Research Letters, doi:10.1029/2011GL047063.

Bingham, R., Hubbard, A., Nienow, P., Sharp, M., 2008. An investigation into the mechanisms controlling seasonal speedup events at a High Arctic glacier. Journal of Geophysical Research 113 (F2), F02006. 
Box, J., Ski, K., 2007. Remote sounding of Greenland supraglacial melt lakes: implications for subglacial hydraulics. Journal of Glaciology 53 (181), 257-265.

Catania, G. A., Neumann, T. A., 2010. Persistent englacial features in the Greenland Ice Sheet. Geophysical Research Letters 37 (2), L02501.

Chen, G., 1999. GPS kinematic positioning for the airborne laser altimetry at Long Valley, California. Ph.D. thesis, Massachusetts Institute of Technology.

Das, S., Joughin, I., Behn, M., Howat, I., King, M., Lizarralde, D., Bhatia, M., 2008. Fracture propagation to the base of the Greenland Ice Sheet during supraglacial lake drainage. Science 320 (5877), 778.

Gumley, L., Descloitres, J., Schmaltz, J., 2003. Creating reprojected true color modis images: A tutorial. University of Wisconsin-Madison.

Hall, D., Nghiem, S., Schaaf, C., DiGirolamo, N., Neumann, G., 2009. Evaluation of surface and near-surface melt characteristics on the greenland ice sheet using modis and quikscat data. Journal of Geophysical Research 114, F04006.

Hall, D.K. Riggs, G., Salomonson, V., May to August 2009. MODIS/Aqua Snow Cover Daily L3 Global 500m Grid, V005. Boulder, CO, USA: National Snow and Ice Data Center. Digital media.

Hanna, E., Huybrechts, P., Steffen, K., Cappelen, J., Huff, R., Shuman, C., Irvine-Fynn, T., Wise, S., Griffiths, M., 2008. Increased runoff from melt from the Greenland Ice Sheet: a response to global warming. Journal of Climate 21 (2), 331-341. 
Hooke, R., Calla, P., Holmlund, P., Nilsson, M., Stroeven, A., 1989. A 3 year record of seasonal variations in surface velocity, Storglaciaren, Sweden. Journal of Glaciology 35 (120), 235-247.

Iken, A., Bindschadler, R., 1986. Combined measurements of subglacial water pressure and surface velocity of Findelengletscher, Switzerland: conclusions about drainage system and sliding mechanism. Journal of Glaciology $32,110$.

Iken, A., Rothlisberger, H., Flotron, A., Haeberli, W., 1983. The uplift of Unteraargletscher at the beginning of the melt season, a consequence of water storage at the bed? Journal of Glaciology 29 (101), 28-47.

IPCC, 2007. Climate Change 2007: the physical science basis: contribution of Working Group I to the Fourth Assessment Report of the Intergovernmental Panel on Climate Change. Cambridge Univ Press.

Joughin, I., Das, S. B., King, M. A., Smith, B. E., Howat, I. M., Moon, T., 2008. Seasonal Speedup Along the Western Flank of the Greenland Ice Sheet. Science 320 (5877), 781-783.

Kamb, B., 1987. Glacier surge mechanism based on linked cavity configuration of the basal water conduit system. Journal of Geophysical Research 92 (B9), 9083-9100.

Kamb, B., Engelhardt, H., Fahnestock, M., Humphrey, N., Meier, M., Stone, D., 1994. Mechanical and hydrologic basis for the rapid motion of a large tidewater glacier 2. Interpretation. Journal of Geophysical Research 99 (B8), 15231. 
King, M., 2004. Rigorous GPS data-processing strategies for glaciological applications. Journal of Glaciology 50 (171), 601-607.

King, R., Bock, Y., 2006. Documentation for the GAMIT GPS analysis software, version 10.3. Mass. Inst. of Technol., Cambridge.

Knap, W., Oerlemans, J., 1996. The surface albedo of the Greenland ice sheet: Satellite-derived and in situ measurements in the Sondre Stromfjord area during the 1991 melt season. Journal of Glaciology 42 (141), $364-674$.

Krabill, W., 2010. IceBridge ATM L2 Icessn Elevation, Slope, and Roughness, [8.5.2010]. Boulder, Colorado USA: National Snow and Ice Data Center Digital Media.

Krawczynski, M., Behn, M., Das, S., Joughin, I., 2009. Constraints on the lake volume required for hydro-fracture through ice sheets. Geophysical Research Letters 36 (10), L10501.

Mair, D., Nienow, P., Willis, I., Sharp, M., 2001. Spatial patterns of glacier motion during a high-velocity event: Haut Glacier d'Arolla, Switzerland. Journal of Glaciology 47 (156), 9-20.

Mair, D., Sharp, M., Willis, I., 2002. Evidence for basal cavity opening from analysis of surface uplift during a high-velocity event: Haut Glacier d'Arolla, Switzerland. Journal of Glaciology 48 (161), 208-216.

McMillan, M., Nienow, P., Shepherd, A., Benham, T., Sole, A., 2007. Seasonal evolution of supra-glacial lakes on the Greenland Ice Sheet. Earth and Planetary Science Letters 262. 
Nienow, P., Hubbard, B., 2006. Surface and Englacial Drainage of Glaciers and Ice Sheets. Encyclopedia of Hydrological Sciences. John Wiley \& Sons.

Nienow, P., Sharp, M., Willis, I., 1998. Seasonal changes in the morphology of the subglacial drainage system, Haut Glacier d'Arolla, Switzerland. Earth Surface Processes and Landforms 23 (9), 825-843.

Palmer, S., Shepherd, A., Nienow, P., Joughin, I., 2011. Seasonal speedup of the Greenland Ice Sheet linked to routing of surface water. Earth and Planetary Science Letters.

Parizek, B., 2010. Glaciology: Sliding to sea. Nature Geoscience 3 (6), 385386.

Parizek, B., Alley, R., 2004. Implications of increased Greenland surface melt under global-warming scenarios: ice-sheet simulations. Quaternary Science Reviews 23 (9-10), 1013-1027.

Phillips, T., Rajaram, H., Steffen, K., 2010. Cryo-hydrologic warming: A potential mechanism for rapid thermal response of ice sheets. Geophysical Research Letters 37 (20), L20503.

Pimentel, S., Flowers, G., 2010. A numerical study of hydrologically driven glacier dynamics and subglacial flooding. Proceedings of the Royal Society A: Mathematical, Physical and Engineering Science doi:10.1098/rspa.2010.0211.

Price, S., Payne, A., Catania, G., Neumann, T., 2008. Seasonal acceleration of inland ice via longitudinal coupling to marginal ice. Journal of Glaciology 54 (185), 213-219. 
Pritchard, H., Arthern, R., Vaughan, D., Edwards, L., 2009. Extensive dynamic thinning on the margins of the Greenland and Antarctic ice sheets. Nature 461 (7266), 971-975.

Röthlisberger, H., 1972. Water pressure in intra- and subglacial channels. Journal of Glaciology 11 (62), 177-203.

Röthlisberger, H., Lang, H., 1987. Glacial hydrology. Glacio-fluvial Sediment Transfer: an Alpine Perspective, 207-274.

Schoof, C., 2010. Ice-sheet acceleration driven by melt supply variability. Nature 468 (7325), 803-806.

Shepherd, A., Hubbard, A., Nienow, P., King, M., McMillan, M., Joughin, I., 2009. Greenland Ice Sheet motion coupled with daily melting in late summer. Geophysical Research Letters 36 (1), L01501.

Stroeve, J., Box, J., Haran, T., 2006. Evaluation of the MODIS (MOD10A1) daily snow albedo product over the Greenland Ice Sheet. Remote Sensing of Environment 105 (2), 155-171.

Sundal, A., Shepherd, A., Nienow, P., Hanna, E., Palmer, S., Huybrechts, P., 2009. Evolution of supra-glacial lakes across the Greenland Ice Sheet. Remote Sensing of Environment 113, 2164-2171.

Sundal, A., Shepherd, A., Nienow, P., Hanna, E., Palmer, S., Huybrechts, P., 2011. Melt-induced speed-up of Greenland Ice Sheet offset by efficient subglacial drainage. Nature 469 (7331), 521-524.

Truffer, M., Harrison, W., March, R., 2005. Record negative glacier balances and low velocities during the 2004 heatwave in Alaska, USA: implications 
681 for the interpretation of observations by Zwally and others in Greenland. $682 \quad J o u r n a l$ of Glaciology 51 (175), 663.

${ }_{683}$ Van de Wal, R., Boot, W., Van den Broeke, M., Smeets, C., Reijmer, ${ }_{684}$ C., Donker, J., Oerlemans, J., 2008. Large and rapid melt-induced ve685 locity changes in the ablation zone of the Greenland Ice Sheet. Science $686 \quad 321(5885), 111$.

${ }_{687}$ Van de Wal, R., Greuell, W., van den Broeke, M., Reijmer, C., Oerlemans, 688 J., 2005. Surface mass-balance observations and automatic weather sta689 tion data along a transect near Kangerlussuaq, West Greenland. Annals 690 of Glaciology 42, 311-316.

691 Van der Veen, C., 2007. Fracture propagation as means of rapidly trans${ }_{692}$ ferring surface meltwater to the base of glaciers. Geophysical Research $693 \quad$ Letters 34 (1), L01501.

${ }_{694}$ Zwally, H., Abdalati, W., Herring, T., Larson, K., Saba, J., Steffen, K., 695 2002. Surface melt-induced acceleration of Greenland ice-sheet flow. Sci$696 \quad$ ence 297 (5579), 218. 


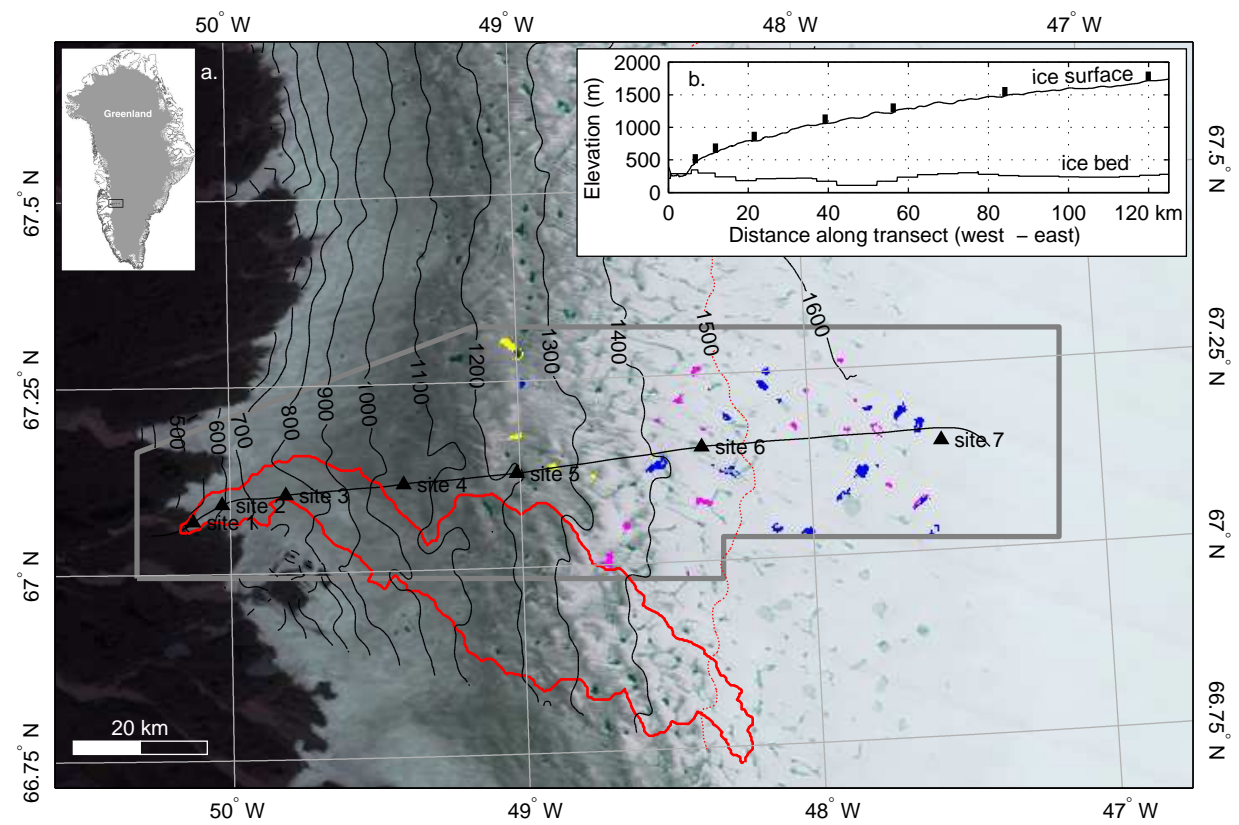

Figure 1: a. Location of the study region on the western margin of the GrIS. The GPS sites are located along a transect across an altitudinal range of 450 - $1700 \mathrm{~m}$ a.s.l. Simultaneous measurements of air temperature and seasonal measurements of ablation were made at each site. The ELA in this region is at $1500 \mathrm{~m}$ (Van de Wal et al., 2005). Contours are produced from a digital elevation model derived from InSAR (Palmer et al., 2011) at 100 $\mathrm{m}$ intervals. Lakes which drain in the interval between sequential MODIS satellite images during the survey period are denoted by coloured patches which represent their surface area immediately prior to drainage (yellow: July 11th-15th; red: July 19th-23rd; blue: July 26th-29th). The region in which lake drainage events were monitored is enclosed by the grey box and the catchment of the river which drains through Leverett glacier and which was also monitored in 2009 is shown in red (Bartholomew et al., in press). b. Ice surface (Krabill, 2010) and bed elevation (Bamber et al., 2001) profiles along the transect (black line, main figure). The locations of the GPS sites are shown by black vertical marks. 


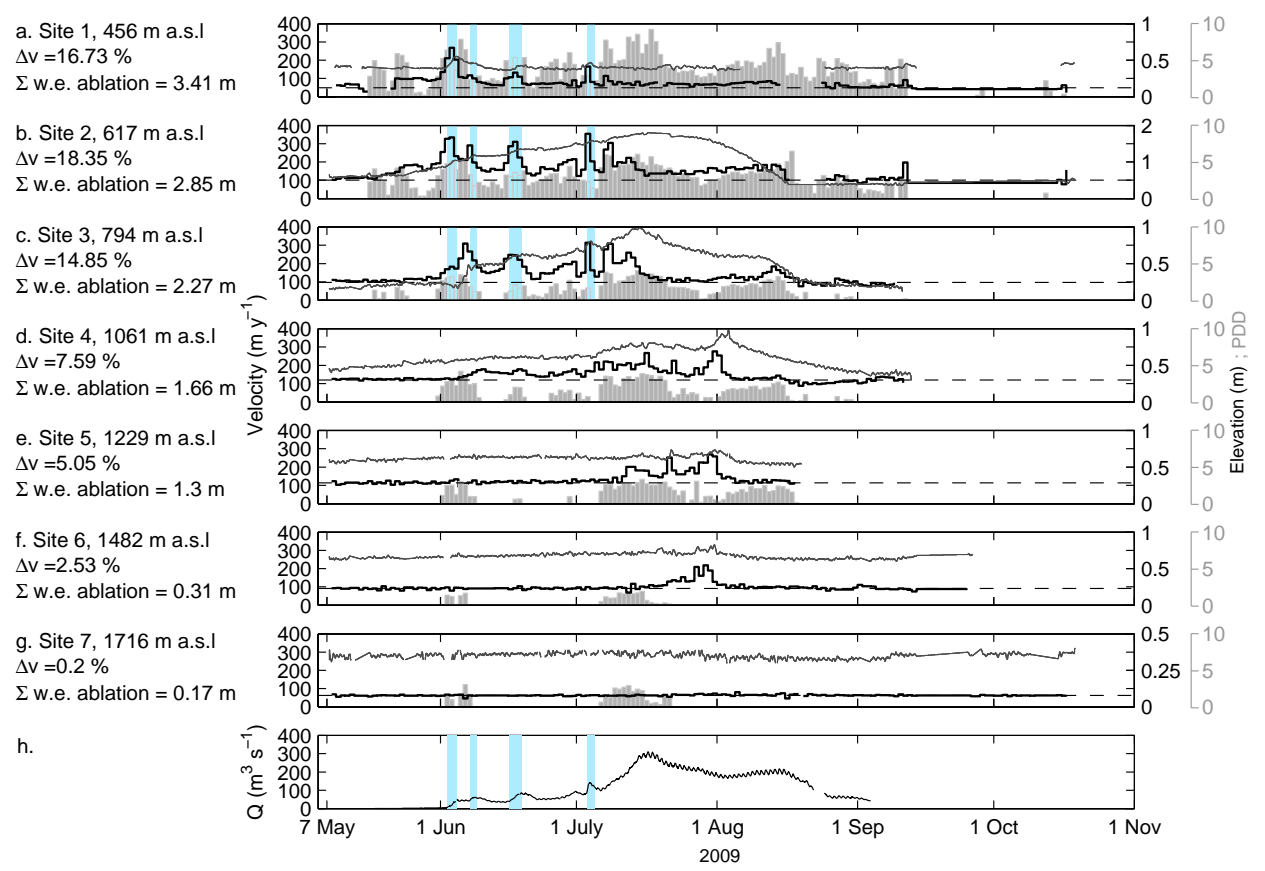

Figure 2: a-g. 24-h horizontal velocity (black stairs), surface height (grey line) and positive-degree days (grey bars) at sites 1-7 for the survey period. The surface height is shown relative to an arbitrary datum, with a linear, surface-parallel, slope removed. Winter background velocity (black dashes) is determined by bulk movement of each GPS site over the subsequent winter. Text to the left of each panel shows the elevation, percentage annual velocity change due to summer velocity variations compared with values if the ice moved at winter rates all year and the total surface ablation in water equivalence at each site for the whole survey period. h. Discharge hydrograph (black; $\mathrm{m}^{3} \mathrm{~s}^{-1}$ ) from Leverett Glacier in 2009. The estimated catchment for this outflow channel (Bartholomew et al., in press) is shown on Figure 1 and contains GPS sites 1,2 and 3. The blue shaded sections identify pulses of meltwater which are associated with dramatic reorganisation and expansion of the subglacial drainage system within the catchment. 


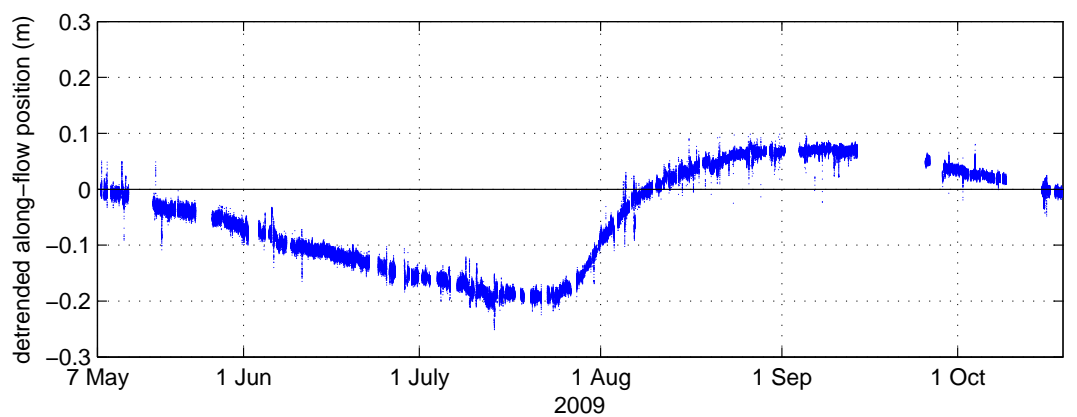

Figure 3: Detrended along-flow position for the GPS at site 7. The residual value indicates the observed distance in metres of the GPS from the expected position if it flowed at its mean rate for the whole survey period. Negative slopes therefore occur when the velocity is slower than the survey period average and vice versa. 

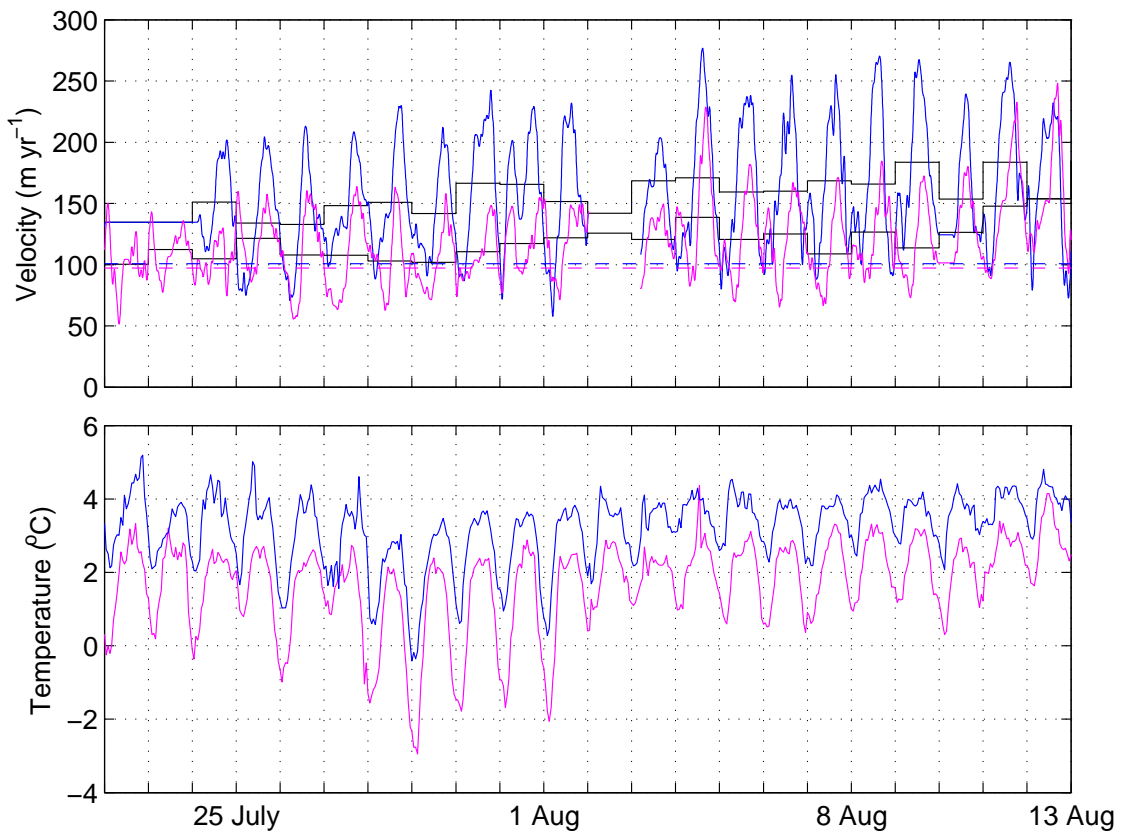

Figure 4: a. Daily cycles in horizontal ice velocities at sites 2 (blue) and 3 (magenta) for $\sim 3$ weeks in late-July/early-August. 24-hour mean velocities are shown by black stairs and coloured lines indicate winter background velocities. b. Temperature record for sites 2 (blue) and 3 (magenta) for the same period. 


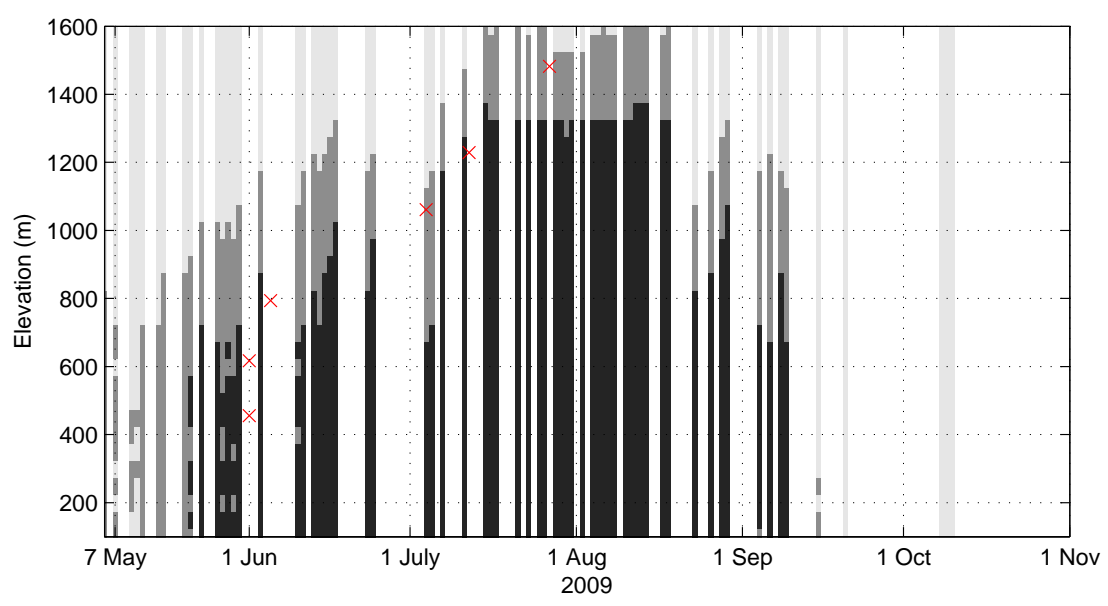

Figure 5: Ice sheet surface conditions inferred using the MODIS MYD10A1 1-day albedo product. Thresholds for bare ice $(<0.45$; black) and snow $(>0.66$; light grey) are used to delimit zones across the study region by elevation (y-axis) throughout the survey period (x-axis). A transitional zone (dark grey) is assumed to comprise a mixture of snow, slush, surface water and bare ice surfaces and broadly delimits the altitudinal extent of surface albedo changes caused by melting of the ice sheet surface (Knap and Oerlemans, 1996). The timing and elevation of the onset of hydrologically forced velocity variations, which occur at sites 1 - 6 successively, is denoted by red crosses. 


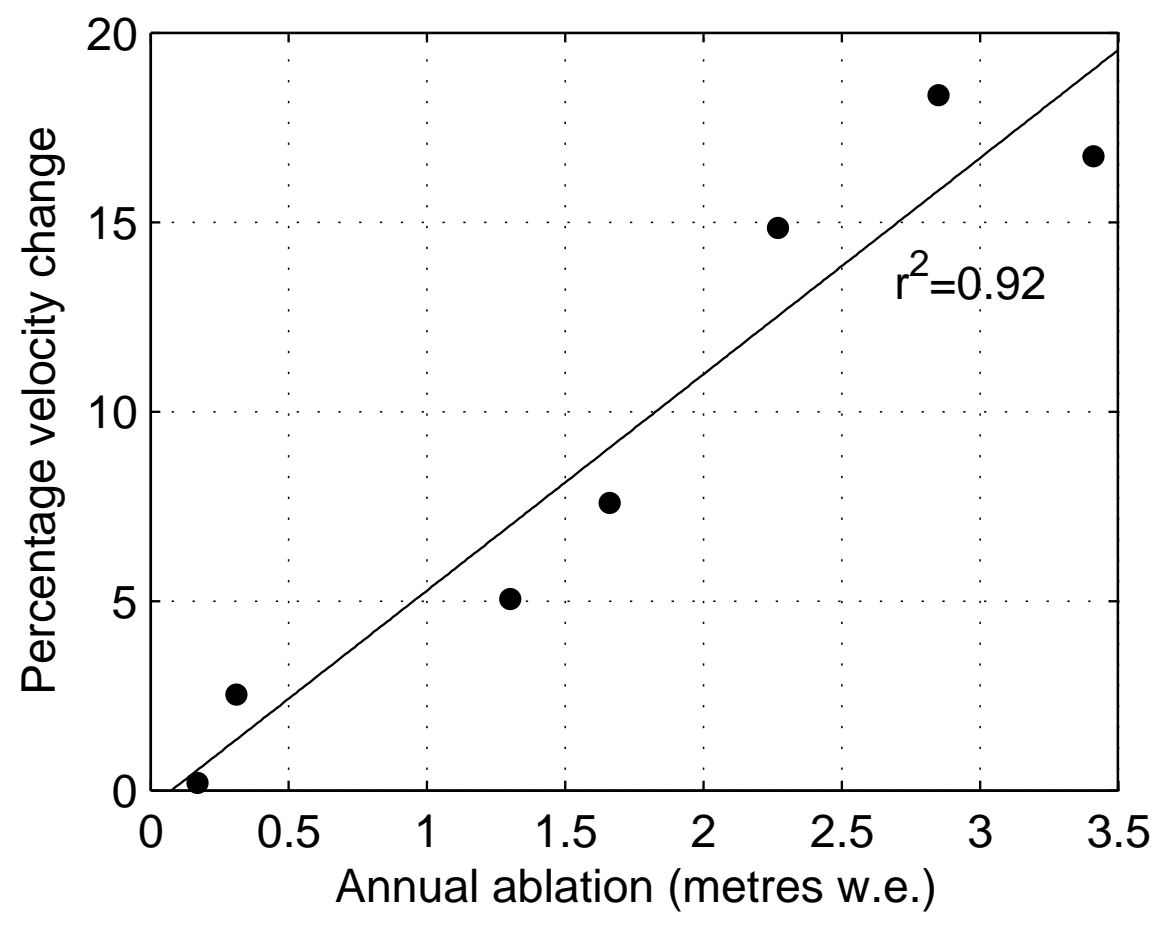

Figure 6: Percentage change in mean annual ice velocity vs. total surface ablation (m w.e.) at the GPS sites. The increase in annual ice velocity is calculated as the percentage by which the observed annual displacement exceeds that which would occur if the ice moved at winter rates all year round. 